\title{
A global renewable mix with proven technologies and common materials
}

\author{
J. Ballabrera (1), A. Garcia-Olivares (2), E. Garcia-Ladona (2), and A. Turiel (2)
}

(1) Unitat de Tecnologia Marina, CSIC, Barcelona, Spain (joaquim@cmima.csic.es, +34 93 2309500), (2) Institut de Ciencies del Mar, CSIC, Barcelona, Spain

A global alternative mix to fossil fuels is proposed, based on proven renewable energy technologies that do not use scarce materials. Taking into account the availability of materials, the resulting mix consists of a combination of onshore and offshore wind turbines, concentrating solar power stations, hydroelectricity and wave power devices attached to the offshore turbines. Solar photovoltaic power could contribute to the mix if its dependence on scarce materials is solved.

Material requirements are studied for the generation, power transport and for some future transport systems. The order of magnitude of copper, aluminium, neodymium, lithium, nickel, zinc and platinum that might be required for the proposed solution is obtained and compared with available reserves. While the proposed global alternative to fossil fuels seems technically feasible, lithium, nickel and platinum could become limiting materials for future vehicles fleet if no global recycling system were implemented and rechargeable zinc-air batteries could not be developed. As much as $60 \%$ of the current copper reserves would have to be employed in the implementation of the proposed solution.

Altogether, the availability of materials may become a long-term physical constraint, preventing the continuation of the usual exponential growth of energy consumption. 